\title{
NOVAS DINÂMICAS DE LAZER: AS FÁBRICAS DE CERVEJA NO RIO DE JANEIRO DO SÉCULO XIX
} (1856-1884)

\author{
NEW LEISURE DYNAMICS: BEER FACTORIES IN 19th-CENTURY RIO DE \\ JANEIRO (1856-1884)
}
NUEVAS DINÁMICAS DE OCIO: LAS FÁBRICAS DE CERVEZA EN EL RIO DE JANEIRO DEL SIGLO XIX (1856-1884)

Victor Andrade Melo*, Thaina Schwan Karls*

Palavras chave:

Atividade de lazer.

Brasil.

Indústria cervejeira.
Resumo: No Rio de Janeiro de meados do século XIX, percebe-se uma maior estruturação de um mercado de entretenimentos, relacionado, inclusive, à conformação de uma sociedade civil que se diversificava socioeconomicamente. Tendo em conta ampliar o olhar sobre essa dinâmica social, este estudo tem por objetivo discutir a experiência de um tipo de estabelecimento que articulava as "artes industriais" com a oferta de alternativas de diversão: fábricas de cerveja localizadas na região central da capital. Trata-se fundamentalmente de uma abordagem histórica da cidade a partir de um de seus divertimentos.

Abstract: In mid-19th-century Rio de Janeiro, an entertainment market emerged related

Keywords:

Leisure activities.

Brazil.

Beer industry.

Palabras clave: Actividad recreativa. Brasil. Industria cervecera. to the establishment of a civil society that was diversifying socioeconomically. In order to broaden perspectives on that social dynamics, this study discusses the experience of one type of business that connected "industrial arts" with a supply of leisure alternatives: beer factories located in Rio's central area. It is a history of the city based on one of its leisure activities.

Resumen: En el Rio de Janeiro de mediados del siglo XIX, se observa una mayor estructuración de un mercado de entretenimiento, relacionado, incluso, a la formación de una sociedad civil que se diversificaba socioeconómicamente. Para extender la mirada sobre esa dinámica social, este estudio tiene el objetivo de discutir la experiencia de un tipo de establecimiento que articulaba las "artes industriales" con la oferta de alternativas de diversión: fábricas de cerveza situadas en la región central de la capital. Se trata básicamente de un abordaje histórico de la ciudad a partir de una de sus opciones de diversión.
*Universidade Federal do Rio de Janeiro. Rio de Janeiro, RJ, Brasil. E-mail: victor.a.melo@uol.com.br; thaina20@ hotmail.com

Recebido em: 01-12-2016 Aprovado em: 11-12-2017

DOI: http://dx.doi.org/10.22456/1982-8918.69803 (c) (1) 은 Licence 


\section{INTRODUÇÃO}

Em meados do século XIX, configurou um novo momento do Brasil a articulação entre 0 aperfeiçoamento da burocracia estatal, o incremento da economia e o fortalecimento dos vínculos com a Europa. No município neutro da Corte, sentiram-se com intensidade os desdobramentos dessas mudanças. No Rio de Janeiro, melhor se expressou a intenção de que o país se tornasse reconhecido pelo seu caráter civilizado. A cidade se fortaleceu como espaço de experiências de modernização e foco irradiador de modas e costumes (SCHWARCZ, 1998).

Nesse cenário, percebe-se uma maior estruturação de um mercado de entretenimentos, relacionado, inclusive, à conformação de uma sociedade civil que se diversificava socioeconomicamente. Essa "devoção ao divertimento" era um aspecto que reforçava a centralidade do Rio de Janeiro:

[...] é na capital, durante os anos de 1840 e 1860, que se cria uma febre de bailes, concertos, reuniões e festas. A corte se opõe à província, arrogando-se o papel de informar os melhores hábitos de civilidade, tudo isso aliado à importação dos bens culturais reificados nos produtos ingleses e franceses (SCHWARCZ, 1998, p. 111).

José de Alencar ironizou esse novo conjunto de "encargos sociais", clamando por uma reestruturação na semana de trabalho:

Se os antigos, que não tinham baile, nem teatros líricos, nem concertos, nem clubes, nem corridas, e que se contentavam com algum sarau de vez em quando, inventaram os dias santos para filarem assim dois dias de descanso, nós, que temos durante a semana todo esse enorme acréscimo de trabalho imposto pela sociedade, nós que já fomos privados dos dias santos, devemos em todo o rigor da justiça lograr mais um dia de descanso, e juntar a terça-feira à segunda, a fim de poder na quinta encerrar o trabalho, com o espírito calmo e o corpo bem disposto (CORREIO MERCANTIL, 1854, p. 2).

Percebe-se mesmo uma diversificação das opções de diversão: bailes (MELO, 2014), práticas esportivas e ginásticas (MELO, 2013; MELO, 2015a; MELO, 2015b; MELO; PERES, 2016), circos (MELO; PERES, 2014; SILVA, 2007), teatros (MARZANO, 2008), entre outras (MARZANO; MELO, 2010; MELO, 2017).

Tendo em conta ampliar o olhar sobre essa dinâmica social observável no Rio de Janeiro do século XIX, mais especificamente sobre a constituição desse mercado de entretenimentos na cidade, este estudo tem por objetivo discutir a experiência de um tipo de estabelecimento que articulava as "artes industriais" com a oferta de diferentes alternativas de diversão: fábricas de cerveja localizadas na região central da cidade.

Interessados na repercussão pública desses estabelecimentos, para alcance do objetivo como fontes utilizamos revistas e jornais publicados no Rio de Janeiro'. Temos clareza da necessidade de usar o veiculado nesses periódicos não como expressão da verdade absoluta, mas, sim, como representações que devem ser consideradas a partir da materialidade do meio consultado (LUCA, 2005). Vale ter em conta que a imprensa já se apresentava como uma arena que repercutia os diferentes posicionamentos sobre as novidades que chegavam ao país.

O recorte temporal tem em conta os objetos investigados - três fábricas de cerveja que se estruturaram como polos de entretenimento no Rio de Janeiro. Uma delas, criada em 1848,

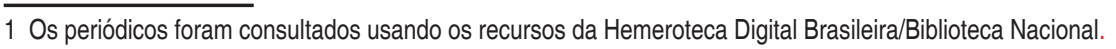


era de propriedade da família Leiden. A outra foi fundada em 1855, por Alexandre Maria VillasBoas. A terceira foi inaugurada em 1864, por Bartholomeu Correa da Silva.

Adotamos como marca inicial do estudo o ano de 1856, a primeira ocorrência em que identificamos um desses estabelecimentos sendo explicitamente apresentado como um espaço de diversão. Já 1884 foi escolhido como marca final por ser o momento em que as três empresas investigadas estavam extintas.

Este estudo trata fundamentalmente de uma história da cidade a partir de um dos seus divertimentos. Sugerimos que as fábricas - em conjunto com outros estabelecimentos, como o Tivoli (localizado no Campo de Santana) - anteciparam em alguns anos o que certas casas ofereceriam mais comumente na década final da centúria, como o Moulin Rouge e a Maison Moderne, ambas de propriedade de Paschoal Segreto (MARTINS, 2010). Foram complexos de entretenimento que bem expressaram um conjunto de importantes mudanças pelas quais passou a capital nacional na segunda metade do século XIX.

\section{CERVEJA: PRIMEIRAS INICIATIVAS FABRIS}

Ainda que existam indícios de que no Brasil já se conhecia a cerveja desde o século XVII, seu consumo somente se tornou difundido a partir da década de 1810, em função da abertura dos portos e da maior presença de ingleses em algumas capitais. 0 produto, todavia, durante muitos anos não logrou popularidade, preterido, por razões culturais e econômicas, pelo vinho português e por licores franceses (entre as elites) e pela cachaça e outras bebidas artesanais, como 0 aluá (entre os populares) (SOUSA, 2004).

Durante anos, a maior parte da cerveja consumida era importada. Nos anos 1830 , surgiram as primeiras experiências de produção da bebida na cidade. Em 1831, anunciou-se a fábrica de propriedade de Pedro Vidal (CORREIO MERCANTIL, 1831, p. 2). Já em 1836, havia a Cerveja Brazileira, estabelecimento que se localizava na Rua de Matacavalos (atual Riachuelo) (JORNAL DO COMÉRCIO, 1836, p. 3), sobre a qual encontramos poucos indícios².

Em 1848, nessa mesma rua, que se localizava numa região fronteiriça do centro, no limite entre o rural e o urbano, a caminho da Tijuca, foi fundada uma empresa que teria maior importância e longevidade: a Fábrica de Cerveja Nacional de Henrique Leiden³ ${ }^{3}$ O proprietário, nascido na Argélia, filho de um pai alemão e uma mãe francesa, com o sucesso do negócio logo abriu um depósito, facilitando a distribuição do produto. Além disso, implantou um sistema de entregas em casa.

Em 1854, Henrique Leiden fundou uma filial em Petrópolis, depois vendida para Henrique Kremer. Nessa década de 1850, outros estabelecimentos congêneres foram inaugurados na capital. Entre esses, merece destaque a Fábrica de Cerveja Nacional de Alexandre Maria Villas-Boas ${ }^{4}$, localizada também na Rua de Matacavalos.

Um ano depois de sua fundação, em 1856, por seus serviços prestados, esse estabelecimento recebeu o título de Imperial, ocasião celebrada por um cronista: "Todas as

\footnotetext{
2 A essa altura, já havia fábricas de cerveja em outras cidades, como, por exemplo, a pertencente a Lima e irmãos, com sede na Bahia (CORREIO OFICIAL, 1835, p. 4)

3 Futuramente, chamar-se-ia Imperial Fábrica Nacional de Cerveja de Henrique Leiden; posteriormente, Imperial e Antiga Fábrica de Cerveja 4 Não conseguimos muitas informações sobre Alexandre Maria. Sabemos que era um comerciante português que faleceu em junho de 1864 (DIÁRIO DO RIO DE JANEIRO, 16 jun. 1864, p. 1).
} 
vezes que um ilustrado monarca, como o nosso, anima por estes atos a indústria do seu país, sem dúvida que abre uma nova fonte de riqueza pública, levanta mais um padrão de glória, grato a seus contemporâneos, e de admiração para os vindouros" (DIÁRIO DO RIO DE JANEIRO, 5 jan. 1856, p. 3).

O contexto ajuda a entender a empolgação do narrador. A promulgação da lei que abolia o tráfico de escravos (1850), por pressões internacionais, notadamente inglesas, aliada à expansão cafeeira, responsável por superávits comerciais, gerou um excedente de recursos a serem investidos, atraindo bancos estrangeiros, induzindo a criação de bancos nacionais, estimulando a diversificação econômica, sendo observável inclusive a ocorrência de um primeiro surto industrial ${ }^{5}$. Além disso, deve-se considerar os efeitos da Tarifa Alves Branco $(1844)^{6}$, que atingiu diretamente as cervejas. 0 aumento da taxação de produtos importados foi mais um estímulo para que a bebida passasse a ser produzida no país.

\section{PRODUÇÃO E DIVERSÃO: UM ESTABELECIMENTO ÚTIL}

As iniciativas fabris eram consideradas como um indício de que progredia o país. Um cronista assim comentou a atuação de Villas-Boas: "Seus esforços têm sido coroados dos mais felizes resultados e, segundo os entendedores, a cerveja de sua fábrica nada deixa a desejar em comparação com a estrangeira, que nos é importada por preço tão alto" (CORREIO MERCANTIL, 1856, p. 1).

Esse empreendimento, todavia, não era somente uma indústria, também oferecendo ao público opções de entretenimento. Vejamos um relato de um anônimo que, a convite do proprietário, visitou a fábrica. Os elogios foram intensos, não só à gentileza dos funcionários como ao fato de que frequentavam o local "famílias respeitadas e moços, que pelo seu trato mostravam ter recebido fina educação" (CORREIO DA TARDE, 1856, p. 3). Chamou-lhe a atenção a conversa animada que se dava não só ao ar livre, à luz do luar, como também no salão, iluminado a gás (encarado como sinal de que o estabelecimento se preocupava em oferecer "confortos modernos").

Jovens fazendo ginástica em aparelhos oferecidos pela fábrica ${ }^{7}$, bem como apresentações musicais e danças, contribuíam para o clima de alegria que no seu olhar reinava:

\footnotetext{
Ao som da música, que tocava ao longo, no alto da montanha, onde os amadores se entregavam aos jogos ginásticos, e da que havia aos lados dos caramanchões, alguns jovens formaram quadrilhas, e é de esperar que para o futuro as senhoras não deixarão de tomar parte em um divertimento que se tem tornado o furor da época (CORREIO DA TARDE, 1856, p. 3).
}

No ponto de vista do frequentador, era mesmo necessário distender as relações entre homens e mulheres para potencializar essas novas possibilidades de diversão. De fato, logo 0 público feminino passou a ser destaque nos eventos no estabelecimento promovidos:

Estamos nos tempos das danças públicas. Domingo passado, na Imperial Fábrica de Cerveja de Matacavalos, se reuniu uma numerosa sociedade. Um madamismo escolhido se deslizava por aquelas compridas escadas, via-se com prazer em

5 Paula (2012) prefere definir o que houve no Rio de Janeiro entre 1840 e 1879 como surto industrial e não efetivamente como industrialização, algo observável no país somente no século XX.

6 Para um bom debate sobre os efeitos da Tarifa, ver Barbosa (2014). 
qualquer dos reservados para a tomada de cerveja donzelas encantadoras, que, quais flores perfumadas, embalsamaram tão aprazível retiro ${ }^{8}$ (CORREIO DA TARDE, 1856, p. 3).

Curiosamente, a única ressalva do empolgado relator foi à qualidade da cerveja: "[...] ainda não é perfeita, como sempre acontece em todas as fábricas novas, mas é de crer que [...] dentro em pouco rivalize com a melhor que nos vem do estrangeiro por exorbitante preço" (CORREIO DA TARDE, 1856, p. 3). Sua avaliação, de toda maneira, foi largamente positiva.

Com esse amplo leque de diversões, o estabelecimento atraiu muita gente. No contexto de uma cidade que crescia, se apresentava como um local de passeio campestre, de contato com a natureza. A companhia anunciava que seus jardins estavam abertos a todos, apenas pagando-se 0 que fosse consumido. Ao comentar essa iniciativa, um jornal sugeriu que se tratava de "mais um divertimento gratuito oferecido aos pobres" (CORREIO DA TARDE, 1856b, p. 1).

Será mesmo que os populares eram bem-vindos à Fábrica? Foi possível identificar que havia certos constrangimentos para os frequentadores. Um indício são esses alertas constantemente inseridos nos anúncios: "Não seadmitirão pessoas que nãoforem decentemente trajadas" (CORREIO DA TARDE, 1856c, p. 2). 0 que significava estar vestido com decência? Que padrão de vestimenta era considerado?

Não conseguimos elementos categóricos para responder tais questões. Percebese, todavia, que a assertiva estava relacionada à definição de um público-alvo que não se restringia às elites, mas que também não era tão amplo. Tinham-se em conta os estratos médios que se conformavam em função da própria diversificação econômica pela qual passava a cidade. Estamos falando de certos profissionais liberais, grupos específicos de funcionários públicos, empregados em cargos intermediários em empresas industriais e comerciais, militares subalternos, donos de pequenos negócios?.

De toda forma, com o decorrer do tempo começaram a também frequentar as fábricas de cerveja indivíduos de setores das camadas populares, trabalhadores de profissões manuais, empregados nas menores posições hierárquicas de empreendimentos de diversas naturezas. Isto é, mesmo com limites, esses estabelecimentos passaram a se constituir em espaços nos quais havia contato entre grupos sociais distintos.

Os elogios ao empreendimento de Alexandre Maria Villas-Boas ressaltavam sempre a iniciativa de conjugar a produção com a diversão:

Entre alguns estabelecimentos que têm sido criados nesta Corte, merece sem dúvida especial menção a fábrica dos Srs. Villas-Boas e C. Neste estabelecimento em que se especula uma nova indústria - a cerveja nacional, encontra também o público um aprazível passeio, mais uma distração em um país onde são tão escassos e dispendiosos os divertimentos (CORREIO MERCANTIL, 1856b, p. 2).

A própria fábrica mobilizou constantemente essa ideia. No Almanak Laemmert de 1857, se anunciou como a melhor do gênero por ser "[...] ao mesmo tempo o mais útil e agradável recreio do respeitável público desta Capital, pela grande chácara, multiplicidade de jogos, como sejam os de bola, bagatela etc." (ALMANAK LAEMMERT, 1857, p. 96).

8 Para um debate sobre a forte presença da dança e sobre o maior protagonismo feminino no Rio de Janeiro da ocasião, ver Melo (2014).

9 Para mais informações, ver Popinigis (2007). 
Nessa mesma edição do Laemmert, há uma grande propaganda da fábrica de Henrique Leiden. A empresa reivindicava o pioneirismo na produção de cerveja e exaltava a qualidade superior de seu produto. Percebe-se que, a essa altura, também oferecia opções de entretenimento:

Achando-se o seu estabelecimento em um dos sítios mais amenos desta Corte, a sua visita se recomenda a todos os amadores de recreios honestos e sociais, os quais, além de ótima cerveja de vários gostos, encontrarão arranjos cômodos, caramanchões, diversos jogos e boa companhia (ALMANAK LAEMMERT, 1857, p. 95).

O seu funcionamento tinha similaridades com o de sua congênere. Frequentemente eram promovidas apresentações musicais, de bandas e orquestras nacionais e internacionais, bem como de exercícios ginásticos, performances dos amadores que usavam os aparelhos oferecidos pela fábrica. Com o decorrer do tempo, em função da constância de espetáculos diversos, a programação passou a ser nos jornais anunciada. Daí para a abertura de um teatro não tardou muito. Em 1861, se chamava Teatro da Imperial e Antiga Fábrica de Cerveja.

Entre as mais constantes se encontravam apresentações no modelo circense, um dos entretenimentos mais valorizados no Rio de Janeiro do século XIX (SILVA, 2007). Nesse estabelecimento funcionou ainda "[...] um grande e novo polyorama, ou vistas dissolutivas [...] de um efeito magnífico" (CORREIO MERCANTIL, 1860, p. 3). Antes das já citadas importantes experiências de Segreto, um dos introdutores do cinema no Rio de Janeiro e no país, a programação da fábrica de Leiden já oferecia atrações visuais.

Em 1861, Leiden apresentou ainda outra novidade. Abriu um "[...] salão para famílias, no qual se acharão todos os sorvetes, gelados, fôetes e mais refrescos da melhor qualidade" (CORREIO MERCANTIL, 1861, p. 3). O proprietário assegurava que eram similares aos oferecidos pelas grandes confeitarias da capital.

Os sorvetes chegaram ao Rio de Janeiro em meados do século XIX. A confeitaria Francioni foi um dos primeiros lugares a fornecer o produto, confeccionado com gelo importado dos Estados Unidos ${ }^{10}$ (CRULS, 1952). Henrique Leiden, todavia, foi um dos pioneiros do país a fabricar o "gelo artificial"11. Com isso pôde oferecer sorvete durante todo ano, além de potencializar a venda de cervejas. Devemos citar que Câmara Cascudo (2004) sugere que a capacidade de gelar essa bebida foi um elemento fundamental na sua popularização.

Tanto Henrique quanto Leon Leiden, que assumiu a direção da fábrica em $1864^{12}$, se tornaram figuras notórias na cidade. 0 segundo foi presidente da Sociedade Francesa de Ginástica e da Sociedade Francesa de Socorros Mútuos, duas agremiações ligadas à colônia de estrangeiros. Ambos foram membros ativos da Sociedade Auxiliadora da Indústria Nacional. $\mathrm{Na}$ Exposição Nacional de 1866, com a qual Leon esteve ativamente envolvido na organização, foi muito elogiada a qualidade de sua cerveja, por alguns considerada como a melhor da cidade (DIÁRIO DO RIO DE JANEIRO, 1866, p. 2).

É importante perceber o quanto esses dois personagens estavam imersos nas tensões que cercaram o processo de industrialização nacional ${ }^{13}$. De toda forma, os Leiden sempre

10 O produto era retirado das geleiras norte-americanas e transportado, envolvido em serragem, nos porões de navios.

11 Pelo decreto de 14 de outubro de 1862, depois de grande debate público, Leiden recebeu o privilégio de explorar o mercado de gelo. Nesse ano, fez várias demonstrações na Escola Central, contando com a presença de deputados, senadores e negociantes (CORREIO MERCANTIL, 1862, p. 1).

12 Não conseguimos saber exatamente porque Leon assumiu o negócio. Não parece que Henrique tenha falecido nessa ocasião. É possível que tenha resolvido morar na Europa, para onde viajava com frequência. Vemos indícios dessa decisão em notícia publicada no Correio Mercantil (1864, p. 3). 
mantiveram seu estabelecimento também como um centro de lazer. Em 1867, a fábrica chegou a receber a visita do Conde D'Eu, que examinou todas as instalações, tanto as fabris quanto as de entretenimento, louvando-a pelas contribuições ao progresso da nação (DIÁRIO DO RIO DE JANEIRO, 1867, p. 3). A empresa adotara, em 1866, a máquina a vapor para a produção de cerveja, sendo reconhecida por tal avanço.

Nesse ínterim, a empresa de Villas-Boas passou por grandes mudanças. Em 1858, fora adquirida por João Gonçalves Pereira Lima ${ }^{14}$, e, no ano seguinte, por Antônio José Gomes Pereira Bastos, que poucos anos antes comprara uma fazenda com o objetivo de introduzir a cultura do lúpulo no Brasil. Seu intuito era fornecê-lo para as fábricas nacionais de cerveja (FRIDMAN, 2002). Em 1859, resolveu se envolver diretamente com a produção da bebida, já com a intenção de manter o espaço de entretenimento.

Em 1861, ampliou os caramanchões, instalou um coreto, aperfeiçoou a iluminação a gás ${ }^{15}$ e construiu um "[...] longo salão, onde se acham montados dois jogos de bola ${ }^{16}$, os mais perfeitos que hoje existem nesta capital" (CORREIO MERCANTIL, 1861b, p. 3). Assumidamente desejava oferecer ao público um "[...] agradável posto de recreio para gozo das famílias e do público, nas horas e dias de descanso".

Da mesma forma, constantemente anunciava a busca de aperfeiçoamento do sabor e da qualidade da cerveja. A partir de 1862, passou a estampar na sua publicidade que recebera medalha de prata na Exposição Nacional de 1861, fazendo questão de alertar o público que sua bebida estava sempre identificada com seu rótulo ${ }^{17}$.

Ilustração 1 - Propaganda da Fábrica de cerveja

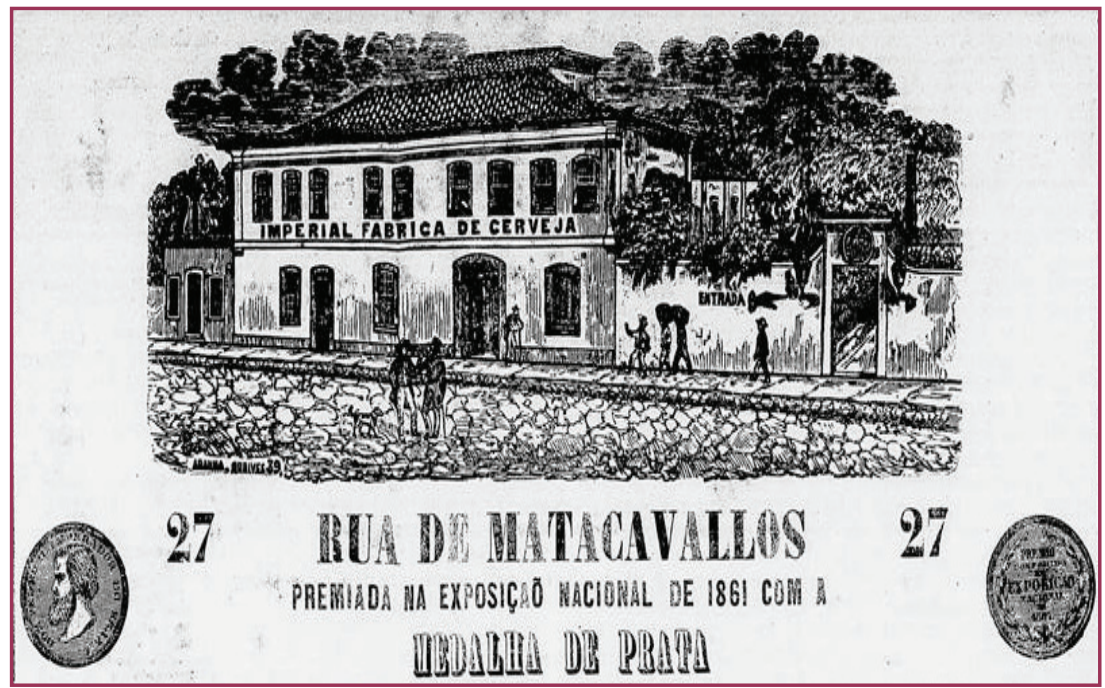

Fonte: Correio Mercantil, 29 de dezembro de 1862, p. 3.

Essa imagem anterior nos dá uma noção de como se organizavam os estabelecimentos: a produção em conjunto com a diversão - do lado esquerdo, a entrada para a venda e para a fábrica; do lado direito, a entrada para a área de entretenimento.

\footnotetext{
14 Negociante de origem portuguesa, tornou-se mais conhecido seu filho homônimo, que chegou a ser Ministro da Agricultura de Venceslau Brás. 15 A fábrica foi elogiada por ter importado um aparelho norte-americano de grande eficiência na iluminação. Isso foi encarado como uma demonstração da sintonia da empresa com os novos tempos (DIÁRIO DO RIO DE JNEIRO, 1863, p. 1).

16 Bastos promoveu alguns torneios da modalidade, como podemos ver nessa nota: "O proprietário desse estabelecimento participa a todos os seus fregueses e amadores do jogo da bola que hoje, 17 do corrente, haverá jogos de prêmios, sendo o primeiro um excelente relógio" (CORREIO MERCANTIL, 1861c, p. 3). Para mais informações sobre tal jogo, ver Melo (2016).

17 Vale destacar que pelos jornais percebe-se que muitos foram os casos de "falsificação" de cerveja. Produzia-se caseiramente (eram muito comuns as marcas "barbantes", de má qualidade), mas vendia-se como se fora importada ou de alguma fábrica nacional mais respeitada.
} 
Ainda que se assemelhassem no funcionamento, as duas empresas parecem ter adotado perfis distintos. $O$ estabelecimento dos Leiden era mais popular, oferecendo maior número de atrações. $O$ de Bastos tinha uma programação mais seletiva, mais restrita a exibições musicais. Próximas uma da outra, localizadas na mesma Rua de Matacavalos, atraíam público amplo e diversificado.

\section{EXPONENCIANDO A IDEIA DE DIVERSÃO}

Nos primeiros anos da década de 1860, outros estabelecimentos semelhantes foram abertos na cidade, como a Fábrica de Cerveja da União, na Rua Nova do Conde (atual Frei Caneca), e o Recreio da Gamboa, na Rua da Harmonia. Merece mesmo destaque a Nova Fábrica de Cerveja Nacional, inaugurada em 1864, na Rua da Guarda Velha (atual 13 de Maio), de propriedade de Bartholomeu Correa da Silva, um importante empresário do entretenimento no Rio de Janeiro do século XIX.

Ele adquiriu, em 1854, o Circo Olympico, que existia desde os anos 1830. Suas iniciativas à frente do negócio o tornaram uma valorizada opção de diversão da cidade:

Bartholomeu se tornou o primeiro grande nome do circo na Corte não só por investir nas instalações da arena (oferecendo conforto e novidades como a iluminação a gás) e por levar seu espetáculo a vários bairros. Fundamentalmente percebeu a conformação de um público que precisava ser atendido na sua busca por emoções (MELO; PERES, 2014, p. 33).

O Circo Olympico tinha uma sede permanente na Rua da Guarda Velha, no mesmo terreno onde Bartholomeu instalaria, em 1871, o Teatro Pedro II, futuro Teatro Lírico (1890), um dos mais importantes da capital na ocasião. A fábrica de cerveja foi instalada na propriedade em frente; no terreno contíguo foram instalados os jardins, integrando um polo de entretenimentos.

O estabelecimento era inspirado nos congêneres existentes no Rio de Janeiro, mas também nos semelhantes que havia nas capitais europeias. De fato, obviamente com peculiaridades, as fábricas de cerveja lembravam algo do funcionamento dos music halls ingleses, um dos símbolos da gestação de uma cultura de massas (JONES, 1989, p. 222).

A publicidade da Nova Fábrica de Cerveja Nacional destacava a elegância das instalações e a beleza de seus jardins sempre ornamentados. A sessão de inauguração já dava uma noção do que seria sua programação: uma banda de música se apresentando no coreto, exibições de sociedades musicais, a performance de uma acrobata da Companhia Bartholomeu, um espetáculo do Circo Olympico e ainda, para terminar, um baile promovido pelo Recreio Guanabarense, uma agremiação que durante muitos anos promoveu atividades no local.

O estabelecimento de Bartholomeu rapidamente ganhou notoriedade. Em um periódico assim se comentou a seu respeito: "Circo Olympico -É digno de proteção, tem bons artistas, bom diretor, boa fábrica de cerveja, que mais se torna preciso? Concorrência, muita concorrência" (O BRASIL, 1865, p. 3). Vejamos como é citado em um importante romance do século XIX, 0 Bom Crioulo, de Adolfo Caminha (2013, p. 35) ${ }^{18}$ :

Saíram juntos, a dar uma volta, nessa noite. Aleixo propôs irem ao Passeio Público tomar um sorvete, um refresco, uma bebida qualquer. Não se podia estar em casa com o calor! D. Carolina lembrou a Guarda Velha: - Não seria melhor irem à Guarda Velha, a fábrica de cerveja? Havia música também...

18 Publicado originalmente em 1895. 
Mas o grumete ponderou que na Guarda Velha estava-se muito à vista, iam marinheiros de bordo, havia muita gente. O Passeio Público era maior e menos frequentado, tinha-se mais liberdade.

Por vezes, é verdade, considerou-se que esse público ampliado criava problemas:

Desordeiros - [...] Estão os vendedores de cerveja servindo à gente que está nas mesas, e lá vem um marinheiro valentão, que, não querendo pagar a cerveja que bebeu, ameaça o caixeiro com pancadas, dizendo que já esteve no Paraguai, e como estivesse no Paraguai, não deve pagar a despesa que faz. É preciso para ali uma força policial para manter a ordem pública (ECHO POPULAR, 1870, p. 3).

$\mathrm{Na}$ trajetória das fábricas de cerveja não foram incomuns conflitos entre os frequentadores. $O$ discurso civilizatório que orientava a experiência nem sempre se manifestava no cotidiano. É possível que o próprio clima de festa e bebedeira contribuísse para gerar alguns "exageros". De toda forma, construiu-se uma representação positiva sobre o estabelecimento da Rua da Guarda Velha: "Onde o respeitável público encontra tudo quanto é comodidade, porque sendo este estabelecimento o primeiro recreio da Corte, se encontra tudo quanto há a desejar para fazer apreciar a bela cerveja, o fresco dos imensos caramanchões que existem nos jardins" (DIÁRIO..., 1871, p. 4). Vejamos que, nesse caso, diferentemente dos outros, menos se falava do aspecto fabril: a diversão era o carro-chefe.

\section{RECONFIGURAÇÕES NA IDEIA DE DIVERSÃO}

Com a criação do Teatro Pedro II, a maior parte da programação da fábrica passou a ser de concertos e bailes promovidos pelo Recreio Guanabarense. Na verdade, nesse momento já havia sensíveis mudanças no perfil do estabelecimento.

O fim do Circo Olympico é um indicador de um processo de melhor definição das esferas de entretenimento na cidade. Ainda que a nova casa mantivesse na programação certas atividades mais populares, como espetáculos circenses, havia a intenção de oferecer atrações mais "sérias", concebidas como superiores do ponto de vista "civilizacional". A Nova Fábrica, por exemplo, passou a acolher exposições artísticas. Não se tratava de abandonar a ideia de entretenimento, mas sim de adotar uma nova conformação. A essa altura, em 1873, Joaquim José Rodrigues Machado tornara-se proprietário do estabelecimento ${ }^{19}$.

O estabelecimento tornou-se ainda mais exaltado como exemplo de bom gosto e progresso. Em 1878, uma matéria o saúda pelas opções de entretenimento:

Edificados os chalets, caramanchões e mesas avulsas, que tanto realce dão à espaçosa área [...], conseguindo deste modo o proprietário consorciar o útil com o agradável, traçando jardins, abrindo vastos salões, que podem conter para cima de 400 pessoas, encontrando estas ali para se distraírem diversos jogos de recreio, variados e honestos divertimentos (O VULGARIZADOR, 1878, p. 190).

Júlia Leiden, viúva de Leon, também promoveu mudanças na fábrica que assumira em 1871. Fundou-se, no seu interior, o Teatro Campestre, com uma função inaugural composta por apresentações dramatúrgicas conduzidas por uma companhia francesa (JORNAL DA TARDE, 1872, p. 4). Claramente era perceptível um processo de "refinamento" da programação. Vejamos um comentário sobre uma das atividades que o estabelecimento passou a acolher:

19 Não conseguimos muitas informações sobre Machado. Era um comerciante de origem lusitana que já estava envolvido com o negócio de cervejas antes de assumir definitivamente a fábrica. 
Aliança Dramática - Sob este título existe nesta Corte uma sociedade particular, composta de moços estudiosos e amantes do teatro. Seus fins é dar espetáculos e soirées familiares. Na quarta-feira 7 do corrente, deu ela uma récita no belo teatrinho da fábrica de cerveja do Sr. Leiden, à Rua do Riachuelo20. [...] 0 prazer, a jovialidade, a alegria e a união imperaram sempre de princípio a fim. O salão magnificamente ornado esteve repleto de convivas de ambos os sexos, e enfim nada faltou para que a dita récita fosse uma festa familiar (CORREIO FLUMINENSE, 1873, p. 3).

A fábrica de Bastos mantinha a programação mais relacionada à música, em muitas ocasiões acolhendo exibições de agremiações amadoras. Em 1879, o Almanak Laemmert não registra mais a existência dessa empresa. $O$ estabelecimento dos Leiden ainda permaneceu aberto por alguns anos, mas logo deixaria de ser da família.

Já a fábrica da Guarda Velha se manteve muita ativa até 1884, quando deixou de existir em função da reforma e ampliação da Rua Senador Dantas. Um cronista registrou esse momento transitando entre o saudosismo e a indignação:

Já a picareta destruiu o belo salão da Guarda-Velha que tanto serviu para obras de caridade, festas, quermesses, bailes, concertos, exposições, quase sempre gratuitamente, porque seu dono, o Sr. Machado, tinha prazer em concorrer com o seu auxílio a todas essas manifestações festivas, sempre dirigidas por distintos cavalheiros, tanto nacionais como estrangeiros (REVISTA ILUSTRADA, 1884, p. 3).

O cronista a saudava como o "[...] rendez-vous da classe burguesa e dos operários que podiam, sem depender de bondes, tomar seu chope de cerveja nacional" (REVISTA ILUSTRADA, 1884, p. 3). Seu fim foi mesmo muito lamentado.

\section{CONCLUSÃO}

No Rio de Janeiro, mesmo que se mantivesse por muitos anos a importação, na década de 1860 já se estabelecera uma alvissareira produção da cerveja: "[...] é um dos ramos da indústria fabril que maior impulso tem tido entre nós nestes últimos tempos, pela propagação do uso desta bebida espirituosa por todas as classes da sociedade" (O AUXILIADOR DA INDÚSTRIA NACIONAL, 1868, p. 267) 21. O Almanak Laemmert de 1869 informa que existiam 13 fábricas na capital, entre as quais as três que citamos em nosso estudo ${ }^{22}$.

Ainda que persistissem algumas críticas à qualidade do produto, cresceu rapidamente o seu consumo. É possível que isso tenha relação com o preço acessível, pelo menos assim sugeriu um cronista - por custar [...] "200 réis a garrafa, e ainda em cima com prato de tremoços [...] ninguém se deve porém queixar porque diabo o público fluminense bebe tanta cerveja!" (CARBONÁRIO, 1882, p. 2).

A popularização da cerveja se deveu tanto ao desenvolvimento de iniciativas de industrialização quanto à estruturação de uma nova dinâmica de entretenimentos, expressões de uma cidade que passava por mudanças. Há que se considerar, nesse cenário, a importância da melhor conformação de um estrato socioeconomicamente intermediário, que ampliou a base de consumo e se tornou um público em potencial para as mais diversas iniciativas. 
As experiências das fábricas de cerveja investigadas foram uma síntese dessas mudanças, bem expressas na articulação entre as ideias de produção e diversão, atraindo um público ampliado, desejoso de aproveitar as novas alternativas geradas pela urbanidade.

Nas décadas finais do século XIX, surgiriam outros polos de entretenimento, como 0 caso dos já citados de propriedade de Paschoal Segreto, bem como muitas outras fábricas de cerveja, algumas até mesmo com estruturas similares às que discutimos. Em 1888, foi inaugurada com grande destaque, inclusive contando com a presença da família imperial, a Brahma, de propriedade de Villiger \& C., que se tornaria um dos mais importantes e longevos estabelecimentos do ramo no Brasil. No futuro, essa empresa também criaria seu espaço de entretenimento ${ }^{23}$.

O que sugerimos é que, em linhas gerais, essas iniciativas seguiram o modelo já consagrado pelos estabelecimentos dos Leiden, de Villas-Boas/Bastos e de Bartholomeu/ Machado. Eles criaram na cidade um novo modelo de entretenimentos.

\section{REFERÊNCIAS}

ALMANAK LAEMMERT, 1857.

ALMANAK LAEMMERT, 1879.

ALMANAK LAEMMERT, 1885.

O AUXILIADOR DA INDÚSTRIA NACIONAL, 1868.

BARBOSA, Pedro Henrique Batista. As Tarifas Alves Branco: entre o protecionismo e a preocupação fiscal. Em Tempo de Histórias, n. 24, p. 60-82, jan./jul. 2014.

O BRASIL, 27 out. 1865 .

CAMINHA, Adolfo. O bom crioulo. Lisboa: Atlântico Press, 2013.

CARBONÁRIO, 4 out. 1882.

CASCUDO, Luís da Câmara. História da alimentação no Brasil. 3. ed. São Paulo: Global, 2004.

CORREIO DA TARDE, 8 abr. 1856.

CORREIO DA TARDE, 25 maio 1856b.

CORREIO DA TARDE, 24 maio 1856c.

CORREIO FLUMINENSE, 15 ago. 1873.

CORREIO MERCANTIL, 15 nov. 1831.

CORREIO MERCANTIL, 1ํ. out. 1854.

CORREIO MERCANTIL, 31 maio 1856.

CORREIO MERCANTIL, $1^{\circ}$. jun. 1856b.

23 Uma interessante abordagem sobre a importância da Brahma pode ser encontrada no estudo de Melo, Araújo e Marques (2003). 
CORREIO MERCANTIL, 19 out. 1860.

CORREIO MERCANTIL, 26 jan. 1861.

CORREIO MERCANTIL, 9 mai. $1861 \mathrm{~b}$.

CORREIO MERCANTIL, 16 e 17 ago. 1861c.

CORREIO MERCANTIL, 15 ago. 1862.

CORREIO MERCANTIL, 16 out. 1864.

CORREIO OFICIAL, 20 mar. 1835.

CRULS, Gastão. Aparência do Rio de Janeiro. Rio de Janeiro: José Olympio, 1952.

DIÁRIO DO RIO DE JANEIRO, 5 jan. 1856.

DIÁRIO DO RIO DE JANEIRO, 7 set. 1863.

DIÁRIO DO RIO DE JANEIRO, 16 jun. 1864.

DIÁRIO DO RIO DE JANEIRO, 30 nov. 1866.

DIÁRIO DO RIO DE JANEIRO, 1ํ.jan. 1867.

DIÁRIO DO RIO DE JANEIRO, 19 fev. 1871.

ECHO POPULAR, 20 fev. 1870.

FRIDMAN, Fania. De chão religioso a terra privada: o caso da Fazenda de Santa Cruz.

Cadernos IPPUR, v. 16, n. 1, p. 311-343, 2002.

JONES, Gareth Stedman. Cultura y política obreras en Londres, 1870-1900: notas sobre la reconstrucción de una clase obrera. In: JONES, Gareth Stedman. Lenguajes de clase. Estudios sobre la historia de la clase obrera inglesa (1832-1982). Madrid: Siglo Veintiuno, 1989. p. 175-236.

JORNAL DA TARDE, 5 fev. 1870.

JORNAL DA TARDE, 27 abr. 1872.

JORNAL DO COMÉRCIO, 27 out. 1836.

LEVY, Maria Bárbara. A indústria do Rio de Janeiro através de suas Sociedades Anônimas. Rio de Janeiro: Editora da UFRJ/Secretaria Municipal da Cidade do Rio de Janeiro, 1994.

LUCA, Tânia Regina de. História dos, nos e por meio dos periódicos. In: PINSKY, Carla Bassanezi (Org.). Fontes históricas. São Paulo: Contexto, 2005. p. 111-153.

MARTINS, William de Souza Nunes. Paschoal Segreto e a criação do mercado de diversão no Rio de Janeiro. In: MARZANO, Andrea, MELO, Victor Andrade de. Vida divertida: histórias do lazer no Rio de Janeiro (1830 - 1930). Rio de Janeiro: Apicuri, 2010. p. 249-274.

MARZANO, Andrea. Cidade em cena: o ator Vasques, o teatro e o Rio de Janeiro (1839-1892). Rio de Janeiro: Folha Seca/FAPERJ, 2008.

MARZANO, Andrea, MELO, Victor Andrade de. Vida divertida: histórias do lazer no Rio de Janeiro (1830 - 1930). Rio de Janeiro: Apicuri, 2010. 
MELO, Hildete Pereira de; ARAUJO, João Lizardo de; MARQUES, Teresa Cristina de Novaes. Raça e nacionalidade no mercado de trabalho carioca na Primeira República: o caso da cervejaria Brahma. Revista Brasileira de Economia, v. 57, n. 3, p. 535-569, set. 2003.

MELO, Victor Andrade de. "Temos apaixonados para o mar e para a terra": representações do esporte nos folhetins (Rio de Janeiro; 1851-1855). Revista Brasileira de Educação Física e Esporte, v. 27, n. 4, p. 553-566, dez. 2013.

MELO, Victor Andrade de. Educação do corpo: bailes no Rio de Janeiro do século XIX: o olhar de Paranhos. Educação e Pesquisa, v. 40, n. 3, p. 751-766, jul./set. 2014.

MELO, Victor Andrade de. Enfrentando os desafios do mar: a natação no Rio de Janeiro do Século XIX. Revista de História da Universidade de São Paulo, n. 172, p. 299-334, jan.jun. 2015a.

MELO, Victor Andrade de. O sport em transição: Rio de Janeiro, 1851-1866. Movimento, v. 21, n. 2, p. 363-376, abr./jun. 2015b.

MELO, Victor Andrade de. Mudanças nos padrões de sociabilidade e diversão: o jogo da bola no Rio de Janeiro (séculos XVIII e XIX). História (São Paulo), v. 35, n. 105, p. 1-23, 2016.

MELO, Victor Andrade de. Uma diversão civilizada: a patinação no Rio de Janeiro do século XIX (1872-1892). Locus, v. 23, n. 1, p. 81-100, 2017.

MELO, Victor Andrade de; PERES, Fabio de Faria. A gymnastica nos tempos do Império. Rio de Janeiro, 7 Letras/Faperj, 2014.

PAULA, João Antônio de. O processo econômico. In: CARVALHO, José Murilo (coord.). História do Brasil Nação (1808-2010). Rio de Janeiro: Objetiva, 2012. v.2: A construção nacional (1830-188

POPINIGIS, Fabiane. Proletários de casaca. Campinas: Editora da Unicamp, 2007.

REVISTA ILUSTRADA, n. 381, 1884.

SCHWARCZ, Lilia Moritz. As barbas do Imperador. São Paulo: Companhia das Letras, 1998.

SILVA, Erminia. Circo-teatro: Benjamin de Oliveira e a teatralidade circense no Brasil. São Paulo: Altana, 2007.

SOUSA, Ricardo Luiz de. Cachaça, vinho, cerveja: da Colônia ao século XX. Estudos Históricos, n. 33, p. 56-75, jan./jul. 2004.

O VULGARIZADOR, 20 jun. 1878. 
